\title{
Environmental sustainability, complex systems, and the disruptive imagination
}

\author{
Thomas P. Seager $\cdot$ Zachary A. Collier • \\ Igor Linkov $\cdot$ James H. Lambert
}

Published online: 31 May 2013

(C) Springer Science+Business Media New York 2013

It is now widely recognized that a scientific approach to the environment requires recognition that all things environmental are embedded in complex systems. While it is theoretically possible to study elements of environmental systems in isolation, the knowledge derived will be of limited value for informing real decisions made in messy, context-rich situations. In environmental systems, it is not typical that all other variables remain equal. Thus, managers, decision-makers, and policy-makers are constrained from adjusting just one variable at a time. The interconnected, interdependent character of real-world environmental systems ensures that simplification risks masking the unintended consequences of decisions. Subsequently, new problems will emerge that require more study, increasingly ambitious interventions, and create further unintended consequences.

An antidote to a spiral of ever-increasing effort yielding increasingly frustrating outcomes might be systems thinking. One goal of systems theory and methodology is to understand interconnectedness and interdependencies at an appropriately holistic scale, remaining sensitive to the

T. P. Seager $(\bowtie)$

Arizona State University, Glendale, AZ, USA

e-mail: Thomas.Seager@asu.edu

Z. A. Collier · I. Linkov

U.S. Army Engineer Research and Development Center,

Vicksburg, MS, USA

e-mail: Zachary.A.Collier@usace.army.mil

I. Linkov

e-mail: Igor.Linkov@usace.army.mil

J. H. Lambert

University of Virginia, Charlottesville, VA, USA

e-mail: jhl6d@virginia.edu limits of knowledge and willing to adapt present and future decisions to new information.

Nonetheless, there is no single template that constitutes a systems approach. The degree to which systems analysts, decision-makers, and scientists can combine reductionist perspectives with holistic perspectives depends on the skill and experience with which methods or tools are employed. The paragraphs below describe several of these, in order from most narrow and quantitative to most broad and necessarily qualitative.

Logical problem-solving requires analysts to pose wellformulated problems that typically yield one best right answer. For example, in systems optimization, the goal to identify a set of design variables that result in minimization or maximization of an objective (or merit) function that represents the values of decision-makers. Famous problems in transportation and economics are amenable to systems optimization, such as planning a bus route that picks up and delivers all passengers while driving the fewest possible miles. Taken collectively, these problems make up a field of study called operations research.

When a systems optimization problem is not reducible to a single objective, it may be amenable to multi-criteria decision analysis (MCDA). Nonetheless, the optimization approach typically makes strong assumptions about the definition of boundaries and state of knowledge of the system, including the relationships among the state variables of the system. Typically, systems optimization is good for managing complicated systems from which reliable data and operational models can be extracted (such as air traffic control, supply chains, or manufacturing); however, it is not often appropriate for complex systems. The latter includes feedback loops that may operate on time scales that render it not useful to conceive of optimality. Some systems can be both simple and complex, in the 
sense that they contain just a few state variables with straight-forward cause-effect relationships, but because of feedback loops, the behavior of the system as a whole is difficult or impossible to predict from examination of the constituent elements separately. The famous Lotka-Volterra difference equations describing predator-prey relationships are one example. Complex systems tend to defy attempts at optimization, but for simple systems, dynamic system models may facilitate adaptive management.

Systems thinking describes an appreciation for the inseverable interdependence of system components, each of which may have its own unique structure, function, and purpose. Analysts with experience of systems thinking will identify connections that are not obvious to others. For example, chlorofluorocarbons (CFCs) were originally heralded as a safe (i.e., nonexplosive), nontoxic, and efficient solution to the problem of specifying working fluids for refrigerators. Only after James Lovelock discovered CFCs in the atmosphere did F. Sherwood Roland and Mario Molina connect them to stratospheric ozone depletion-a realization that eventually resulted in award of the Nobel Prize (along with Paul J. Crutzen). Where such systems thinking is especially useful in expanding the boundaries of logical problem-solving by including new information, new realizations, and updated understanding, so as to mitigate the unintended consequences inevitably resulting from simpler approaches.
Lateral thinking describes a process that moves beyond the preoccupation with optimization resulting in a single best answer. The key to lateral thinking is recognizing that the solution to any systems problem depends upon how the problem is formulated. For example, in operations research, selection of the problem boundaries and objective function dictates the best solution. Therefore, several decision-makers or stakeholders vested in any environmental problem may disagree on the best alternative. Lateral thinking recognizes that reframing the problem will alter the solution set and might break a deadlock between parties that otherwise would remain locked in an interminable dispute. Lateral thinking may be most appropriate when confronted with wicked problems (Seager et al. 2012, Rittell and Webber 1973). Here, problem formulation and solution creation happen simultaneously. For example, if the problem of crime is posed as a failure of public education, then the solution suggested by this formulation of the problem is obviously education improvement. Lateral thinking suggests that alternative problem formulations and solutions are possible and encourage analysts to explore possibilities that resist overspecification.

Finally, what we will call Big Bang thinking goes further than lateral thinking to include the highly imaginative exercises like futurism and science fiction. Here, the described system may not even be possible. For example, big bang thinking is not constrained by the second law of

Table 1 A suggested categorization of publications in this special issue

Logical problem-solving Can be complicated and systems-oriented, as in operations research problems that seek to maximize efficiency

Lindhe et al. (2013) Uncertainty modeling in multi-criteria analysis of water safety measures

Kaffashi et al. (2013) Non-users' trade-offs between natural scenery, water quality, ecological functions and biodiversity conservation: A way to preserve wetlands

Collier et al. (2013) Sustainable roofing technology under multiple constraints: A decision analytical approach

Harmon and Viles Beyond geomorphosites: Tradeoffs, optimization, and networking in heritage landscapes

(2013)

Merad et al. (2013)

Systems thinking

Multiple criteria decision aiding framework to analyze and assess the governance of sustainability

Mendoza and Clemen

Sees connections between things that previously were thought to be unrelated, such as the rebound effect

(2013)

Wang et al. (2013)

Outsourcing sustainability: a game-theoretic modeling approach

Reboredo (2013)

Support of sustainable management of nitrogen contamination due to septic systems using numerical modeling methods

Lateral thinking

Socio-economic, environmental and governance impacts of Illegal logging.

Reframes the problem. Breaks patterns of thought, redefines boundaries, and reveals unstated assumptions. Appropriate for wicked problems.

Jennings et al. (2013) Resilience certification for commercial buildings: A study of stakeholder perspectives

Scanlon et al. (2013)

Introducing a streamlined life cycle assessment approach for evaluating sustainability in defense acquisitions

Fehr and Santos (2013) Source separation driven reverse logistics in MSW management

Big bang thinking Highly imaginative, including science fiction. Might be unrealistic or even impossible, but stimulates the moral and technical imagination.

Typically unpublishable in the peer-reviewed science literature, except in rare editorials, opinion pieces, or speech transcripts from prestigious academics. 
thermodynamics. Analysts will sometimes purposefully engage in brainstorming to tap into big bang thinking. One of the rules of brainstorming is that ideas should flow uncensored and unjudged, so as to free the creative process from preconceived notions or prior constraints. Big bang thinking stimulates the moral and technical imagination that steers future system trajectories toward more desirable outcomes.

This special issue of Environment, Systems and Decisions has selected papers that relate to the evolving concept of sustainability (Seager 2008). The papers presented can be loosely characterized as representing different examples of the types of systems approaches described above (Table 1). The most common approach is logical problemsolving, although the papers represented here are not satisfied to present a single best solution. Rather, they emphasize analysis of tradeoffs between competing objectives (Kaffashi et al. 2013; Collier et al. 2013; Harmon and Viles 2013; Merad et al. 2013). Systems thinking approaches are also well-represented. Here, the emphasis is on study of the interdependencies of different agents or components in a system that might otherwise be studied separately (Mendoza and Clemen 2013; Wang et al. 2013), thereby expanding understanding of systemic causes and consequences. Nonetheless, sustainability demands even more imaginative (and difficult to quantify) systems approaches. The last category of papers represented in this issue includes those that attempt to reframe problems that have previously been examined only under narrow boundaries. For example, Jennings et al. (2013) put forth an understanding of engineering resilience that represents a significant departure from all but a few prior thinkers. Scanlon et al. (2013) propose a method for framing that is best applied early in problem formulation stages to ensure that boundaries are not drawn too narrowly, while Fehr and Santos (2013) provide an examination of waste diversion that acknowledges the role of waste pickers that has previously been given scant attention by policy-makers.

We invite and welcome the readers of Environment Systems \& Decisions to consider how and whether big bang thinking-the most disruptive and imaginative systems approach of them all-might be manifested or emergent in this special issue, and forthcoming issues. As noted in Table 1, there is considerable resistance in academic circles to acknowledge big bang thinking as legitimate scholarship. Nonetheless, it is this type of thinking that often yields what Costanza (2001) calls the "preanalytic vision" on which all scientific analysis is based. Thus, it is impossible to fully understand the limitations and potential of the logical problem-solving, or any systems approach, without being able to traverse the full spectrum of systems approaches. It is only in this way that analysts and decision-makers can decide which approaches are useful and appropriate for the particular problem or opportunity at hand.

\section{References}

Collier ZA, Wang D, Vogel JT, Tatham EK, Linkov I (2013) Sustainable roofing technology under multiple constraints: a decision-analytical approach. Environ Syst Decis 33(2). doi: 10.1007/s10669-013-9446-5

Costanza R (2001) Visions, values, valuation, and the need for an ecological economics. BioScience 51(6):459-468

Fehr M, Santos FC (2013) Source separation-driven reverse logistics in MSW management. Environ Syst Decis 33(2). doi:10.1007/s 10669-013-9441-x

Harmon BA, Viles H (2013) Beyond geomorphosites: trade-offs, optimization, and networking in heritage landscapes. Environ Syst Decis 33(2). doi:10.1007/s10669-013-9448-3

Jennings BJ, Vugrin ED, Belasich DK (2013) Resilience certification for commercial buildings: a study of stakeholder perspectives. Environ Syst Decis 33(2). doi:10.1007/s10669-013-9440-y

Kaffashi S, Shamsudin MN, Radam A, Rahim KA, Yacob MR (2013) Non-users' trade-off between natural scenery, water quality, ecological functions and biodiversity conservation: a way to preserve wetlands. Environ Syst Decis 33(2). doi:10.1007/s 10669-013-9436-7

Lindhe A, Rosén L, Norberg T, Røstum J, Pettersson TJR (2013) Uncertainty modelling in multi-criteria analysis of water safety measures. Environ Syst Decis 33(2). doi:10.1007/s10669-0139442-9

Mendoza AJ, Clemen RT (2013) Outsourcing sustainability: a gametheoretic modeling approach. Environ Syst Decis 33(2). doi: 10.1007/s10669-013-9443-8

Merad M, Dechy N, Marcel F, Linkov I (2013) Multiple-criteria decision-aiding framework to analyze and assess the governance of sustainability. Environ Syst Decis 33(2). doi:10.1007/s10669013-9447-4

Reboredo F (2013) Socio-economic, environmental, and governance impacts of illegal logging. Environ Syst Decis 33(2). doi:10.1007/s 10669-013-9444-7

Rittel HW, Webber MM (1973) Dilemmas in a general theory of planning. Policy Sci 4(2):155-169

Scanlon KA, Cammarata C, Siart S (2013) Introducing a streamlined life cycle assessment approach for evaluating sustainability in defense acquisitions. Environ Syst Decis 33(2). doi:10.1007/s 10669-013-9450-9

Seager TP (2008) The sustainability spectrum and the sciences of sustainability. Bus Strat Environ 17(7):444-453

Seager T, Selinger E, Wiek A (2012) Science for wicked problems: understanding sustainability science and the role of interactional expertise. J Agr Environ Ethic 25(4):467-484

Wang L, Ye M, Lee PZ, Hicks RW (2013) Support of sustainable management of nitrogen contamination due to septic systems using numerical modeling methods. Environ Syst Decis 33(2). doi:10.1007/s10669-013-9445-6 